\title{
Effects of Transapical Transcatheter Mitral Valve Implantation
}

\author{
Ming-Chon Hsiung ${ }^{1}$, Wei-Hsian Yin ${ }^{1,2}$, Yung-Tsai Lee ${ }^{1,3}$, Tien-Ping Tsao ${ }^{1,4}$, \\ Kuo-Chen Lee ${ }^{1,4}$, Kuan-Chih Huang ${ }^{1}$, Pei-En Chen ${ }^{5,6}$, Wei-Hsuan Chiang ${ }^{1}$, Tao-Hsin Tung ${ }^{7}$ \\ and Jeng Wei ${ }^{1,4 *}$ \\ ${ }^{1}$ Heart Center, Cheng Hsin General Hospital, Taipei, Taiwan, ${ }^{2}$ Faculty of Medicine, National Yang Ming University, Taipei, \\ Taiwan, ${ }^{3}$ School of Medicine, Institute of Microbiology and Immunology, National Yang Ming University, Taipei, Taiwan, \\ ${ }^{4}$ Faculty of Medicine, National Defense Medical Center, Taipei, Taiwan, ${ }^{5}$ Institute of Health Policy and Management, National \\ Taiwan University, Taipei, Taiwan, ${ }^{6}$ Taiwan Association of Health Industry Management and Development, Taipei, Taiwan, \\ ${ }^{7}$ Department of Medical Research and Education, Cheng Hsin General Hospital, Taipei, Taiwan
}

OPEN ACCESS

Edited by:

Tomas Antonio Salerno University of Miami, United States

Reviewed by: Antonino S. Rubino,

University of Campania Luigi

Vanvitelli, Italy

Antonio Miceli,

Istituto Clinico Sant'Ambrogio, Italy

*Correspondence:

Jeng Wei

jengwei@mac.com

Specialty section: This article was submitted to

Heart Surgery,

a section of the journal

Frontiers in Cardiovascular Medicine

Received: 25 November 2020 Accepted: 28 April 2021

Published: 11 June 2021

Citation:

Hsiung M-C, Yin W-H, Lee $Y-T$,

Tsao T-P, Lee K-C, Huang K-C,

Chen P-E, Chiang W-H, Tung T-H and

Wei J (2021) Effects of Transapical

Transcatheter Mitral Valve Implantation.

Front. Cardiovasc. Med. 8:633369.

doi: 10.3389/fcrm.2021.633369
Purpose: In this study, transapical transcatheter mitral valve-in-valve implantation (TAMVI) was compared with surgical redo mitral valve replacement (SRMVR) in terms of clinical outcomes.

Methods: We retrospectively identified patients with degenerated mitral bioprosthesis or failed annuloplasty rings who underwent redo SRMVR or TAMVI at our medical center. Clinical outcomes were based on echocardiography results.

Results: We retrospectively identified patients with symptomatic mitral bioprosthetic valve dysfunction $(n=58)$ and failed annuloplasty rings $(n=14)$ who underwent redo SRMVR $(n=36)$ or TAMVI $(n=36)$. The Society of Thoracic Surgeons Predicted Risk of Mortality scores were higher in the TAMVI group (median: 9.52) than in the SRMVR group (median: 5.59) ( $p$-value $=0.02$ ). TAMVI patients were more severe in New York Heart Association ( $p$-value $=0.04$ ). The total procedure time (skin to skin) and length of stay after procedures were significantly shorter in the TAMVI group, and no significant difference in mortality was noted after adjustment for confounding factors $(p$-value $=0.11)$. The overall mean mitral valve pressure gradient was lower in the TAMVI group than in the SRMVR group at 24 months $(p<0.01)$. Both groups presented a decrease in the severity of mitral and tricuspid regurgitation at 3-24 months.

Conclusions: In conclusion, the statistical analysis is still not robust enough to make a claim that TAMVI is an appropriate alternative. The outcome of the patient appears only to be related to the patient's pre-operative STS score. Additional multi-center, longitudinal studies are warranted to adequately assess the effect of TAMVI.

Keywords: mitral valve implantation, surgical redo mitral valve replacement, cardiac surgery, heart surgery, cardiovascular

\section{INTRODUCTION}

Over the past two decades, transcatheter aortic valve implantation (TAVI) has been established as a viable alternative treatment to deal with severe aortic stenosis in patients at risk of open-heart surgery. This procedure has also been extended to patients facing low-to-intermediate operative risk. This shift has been prompted by recent studies suggesting that TAVI provides survival benefits for high-risk and intermediate-risk patients (1). Mitral valve disease is the most common 
valvular disease in developed countries. There has been a notable shift away from mechanical valves toward bioprosthesis valves, despite their finite longevity. Recurrent mitral regurgitation $(\mathrm{MR})$ is frequently encountered after mitral valve repair, particularly in cases of ischemic MR (2). However, reoperation imposes high risks among the aged and those with multiple comorbidities. Transapical transcatheter mitral valve-in-valve implantation (TAMVI) is now regarded as a promising alternative treatment for patients with degenerated bioprosthesis or failed annuloplasty (3). Most cases of TAMVI were reported in large registry and were done in some referral centers. The surgery was only reported with limited cases in Asian patients $(4,5)$. There have been a relatively small number of reports pertaining to the clinical outcomes and echocardiographic findings following TAMVI or surgical redo mitral valve replacement (SRMVR) for degenerated bioprosthetic valve or failed annuloplasty rings. In this study, we sought to determine whether TAMVI could achieve outcomes on par with those of SRMVR at 3, 6, 12, and 24 months after the procedure in terms of mortality rates and echocardiographic findings.

\section{METHODS AND MATERIALS}

\section{Study Subjects and Data Collections}

We retrospectively identified patients who underwent SRMVR or TAMVI for degenerated mitral bioprosthesis or failed annuloplasty rings at our medical center between 1998 and July 2018. Note that the TAMVI procedure was not performed until 2014 (Figure 1). In the SRMVR group, myocardial protection was achieved via aortic clamping and antegrade cardioplegia. The left atrium was approached via Waterson's groove or transseptal (in cases where tricuspid intervention was required). Following replacement, the left atrium was closed and warmed cardioplegia was delivered prior to removal of the aortic cross clamp. Once the heart started beating and all vital signs were satisfactory, cardio pulmonary bypass (CPB) was weaned off and the sternum was closed. In the TAMVI group, all procedures were conducted using the transapical approach. All procedures were performed using general anesthesia under $2 \mathrm{D}$ and $3 \mathrm{D}$ transesophageal echocardiography guidance (TEE). The left ventricle apex was guided via Transthoracic Echo and agitated normal saline $(2 \mathrm{cc})$ was injected into the left ventricle using a fine needle, whereupon a left anterior thoracotomy was performed through the fifth or sixth intercostal space. A guidewire was advanced through two 3-0 polypropylene purse string surfaces reinforced with Teflon pledget, across the malfunctioning bioprosthesis into the pulmonary vein. This procedure was performed solely under $2 \mathrm{D}$ or $3 \mathrm{D}$ TEE with no iodinated contrast. A stiffer guidewire (Amplatz Extra stiff; Cook Inc., Bloomington, IN) was then

Abbreviations: TAMVI, transapical transcatheter mitral valve-in-valve implantation; SRMVR, surgical redo mitral valve replacement; NYHA, New York Heart Association; MR, mitral regurgitation; $\mathrm{CPB}$, cardio pulmonary bypass; TEE, trans-esophageal echocardiography; MVARC, Mitral Valve Academic Research Consortium; MDCT, multidetector computed tomography; IPTW, inverse probability of treatment weighting; LVOT, left ventricular outflow tract; TMVIR, the mitral valve in ring; MVARC, Mitral Valve Academic Research Consortium. introduced using a Judkins catheter for protection. An Edwards Sapien, Sapien XT, Sapien S3 (Edwards Lifesciences, Irvine, CA), or Lotus (Boston Scientific) was delivered using the standard delivery system (Ascendra, Ascendra +, Commander; Edwards Life sciences) during rapid ventricular pacing 130-180 BPM.

All of the patients included in this study had degenerated mitral bioprosthesis or failed annuloplasty rings. The treatment method was determined by a multi-disciplinary heart team in accordance with the anticipated risk and anatomical specifics of each patient. Echocardiographic parameters were reported in accordance with the guidelines defined by the American Society of Echocardiography and the Mitral Valve Academic Research Consortium (MVARC) consensus document (6-8). All transcatheter procedures were performed using a balloon-expandable transcatheter heart valve (Edward Sapien 3, XT) or heart valve (Lotus, Boston Scientific), which was manually implanted via transapical access, as previous described (9-11). The access route and valve size were based on procedural echocardiographic findings and multidetector computed tomography (MDCT). The exclusion criteria included active endocarditis, cases requiring concomitant procedures for aortic disease or coronary artery disease. We also excluded the patients with a measured new-left ventricular outflow tract area (new-LVOT) $<150 \mathrm{~cm}^{2}$ at end-systolic phase and aortic-mitral angle $<135^{\circ}(12)$.

Sample data included detailed clinical information on 72 patients, 36 of whom underwent TAMVI (50\%) and 36 of whom underwent SRMVR with cardiopulmonary bypass (50\%). Valve type was determined prior to the procedure, whereas valve size was determined during the procedure by calculation with proprietary valve size. None of the patients who needed concomitant aortic valve replacement or had prosthetic valves developed mitral valve endocarditis (in the time period).

In this study, all patient information, outcomes, and complications were derived from electronic medical records. This study was approved by the Regional Ethical Review Board and all patients provided written informed consent.

\section{Statistical Analysis}

Continuous variables were reported as mean \pm SD or median (range) and tested using a two-sample independent $t$-test or Mann-Whitney $U$ test, respectively. Categorical variables were examined using the chi-square test or fisher's exact test. A repeated measures analysis of variance and McNemar's test were performed to clarify the results of the echocardiographic findings between the SRMVR and TAMVI groups. Survival curves were analyzed using the Kaplan-Meier method and compared using the log-rank test. A two-sided $p$-value of $<0.05$ was considered statistically significant. All statistical analysis was performed using IBM SPSS statistics, version 20 (IBM, Armonk, NY).

In addition, the estimates of screening for important variables using univariable cox regression and including the significant variables is not the ideal way to approach model construction. Because subjects in the TAMVI and SRMVR groups likely differ for confounding factors and differences in outcomes could reflect differences in baseline conditions rather than a real treatment 


\section{Surgical Case}

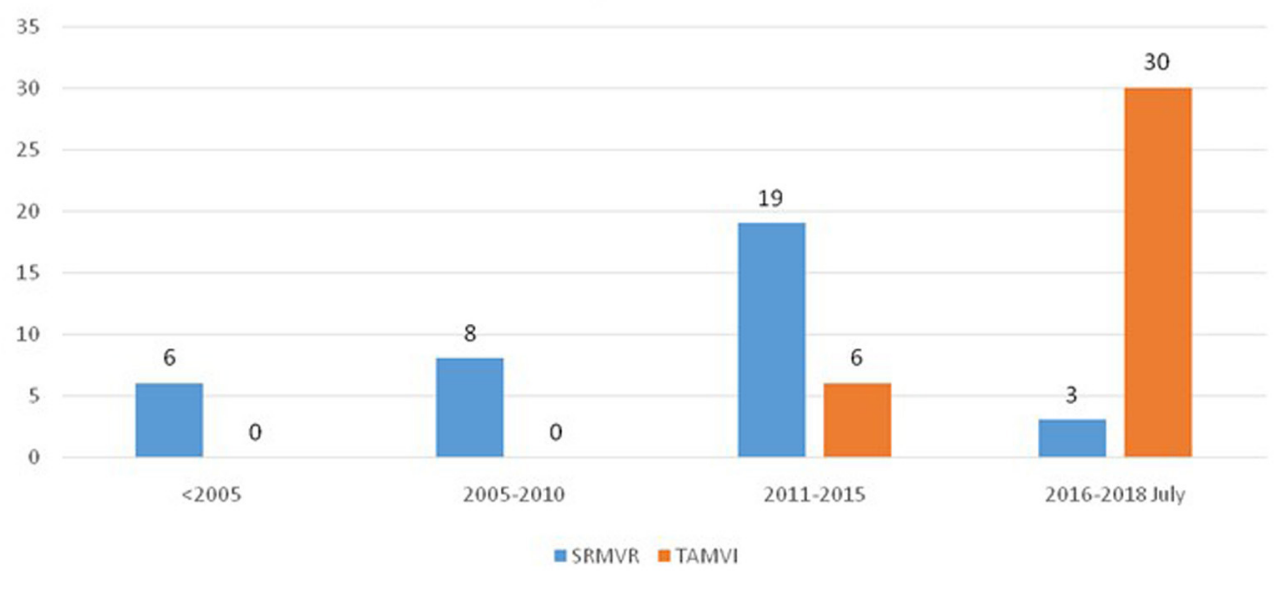

FIGURE 1 | Change of the number of TAMVI compared with SRMVR in the study hospital $(n=72)$.

effects, inverse probability of treatment weighting (IPTW) was used to compare the two treatments (13).

\section{RESULTS}

In this study, a total of 72 redo mitral valve replacement patients (TAMVI: $n=36$; SRMVR: $n=36$ ) met the inclusion criteria, including patient characteristics and operative data. Studypatients TAMVI $(30 / 36=83.3 \%)$ exhibited a more-pronounced proportion after 2016 than SRMVR $(3 / 36=8.3 \%)$ (Figure 1). Table 1 lists the baseline characteristics of the study population. The age difference is not statistically significant between patients who underwent TAMVI implantation and underwent SRMVR $(65.28 \pm 13.89$ vs. $59.61 \pm 15.92, p=0.11)$. In addition to higher median STS Predicted Risk of Mortality scores (9.52 [range: $1.16-78.41$ ] vs. 5.59 [range: $1.12-44.15$ ], $p=0.02$ for Mann-Whitney $U$ test), TAMVI patients are also more likely to have liver disease, $\mathrm{CAD}$, and severe heart failure. Indications for reoperation included recurrent severe mitral regurgitation in 16 patients $(22.2 \%)$, isolated mitral stenosis in $44(61.1 \%)$, and mixed mitral regurgitation and stenosis in 12 (16.7\%).

Procedural details for surgical intervention are summarized in the Table 2. The main proportion of replacing valve type were STJUDE (44.4\%) and Edwards Sapien XT (63.9\%) in the SRMVR and TAMVI groups, respectively. Table 3 further indicates the comparisons of in-hospital outcomes between SRMVR and TAMVI groups. To compare the TAMVI groups, SRMVR groups had longer total procedure time $(520.97 \pm 85.56 \mathrm{~min}$ vs. $177.50 \pm$ $115.86 \mathrm{~min}, p<0.001)$ and longer length of stay after procedures $(28.47 \pm 12.15 \mathrm{~min}$ vs. $21.89 \pm 8.60 \mathrm{~min}, p=0.01)$. There was one case of stroke after SRMVR but no cases of stroke after TAMVI. There were no indications of left ventricular outflow tract (LVOT) obstruction in either group. There were no significant differences between the two groups in terms of bleeding or arrhythmia. In addition, the mean cardiopulmonary bypass duration was $181.97 \pm 63.20 \mathrm{~min}$, whereas the aortic clamp duration was $153.39 \pm 66.96 \mathrm{~min}$. Tricuspid valve repair was performed as a concomitant procedure in six cases and ablation for atrial fibrillation in five cases, based on the judgment of the operating surgeon.

Table 4 indicates the no statistical significantly for the comparisons of in-hospital outcomes between the two TAVI products. As Table 5 shows, only borderline significant was found in total ICU stay between failed annuloplasty ring and non-failed annuloplasty $(12.33 \pm 13.65$ vs. $3.76 \pm 4.43$ days, $p=0.05$ for Mann-Whitney $\mathrm{U}$ test). In addition, in the mitral valve in ring (TMVIR) groups, we did three patients, all patients under TAMVI implantation with two Edwards Sapien XT and one Boston Scientific Lotus valve. As shown in Table 6, two of these patients were event-free; however, one of the patients expired 21-day post-operation due to multiple organ failure (STS score $=73.665$ ).

As shown in Figures 2A-D, hemodynamic results were deemed satisfactory based on a significant reduction in the mean pressure gradient, transmitral prosthesis gradient, and right ventricular systolic pressure for both SRMVR and TAMVI groups. The significant lower were found of these three hemodynamic results in the SRMVR groups than TAMVI groups ( $p$-value for the repeated ANOVA $<0.001$ ). Figure 2E shows that TAMVI groups had lower right ventricular ejection fraction than SRMVR groups during 24-month follow-up ( $p=0.005$ ).

Figure 3 shows that the degrees of mitral regurgitation significantly regress to mild or none only after 3 months in both SRMVR $(3 \mathrm{~A})(p=0.02)$ and TAMVI $(3 \mathrm{~B})(p=0.02)$ groups. No significant changes were found based on the multiple comparisons. The disparity of tricuspis regurgitation was found between SRMVR (3C) and TAMVI (3D) groups.

As Figure 4 shows, in the SRMVR patients, the 3-, 6-, 12-, and 24-month cumulative mortality were $2.8 \%$. In TAMVI patients, the 3-, 6-, 12-, and 24-month cumulative mortality 
TABLE 1 | Baseline clinical characteristics between SRMVR and TAMVI groups $(n=72)$.

\begin{tabular}{|c|c|c|c|}
\hline & SRMVR $(n=36)$ & TAMVI $(n=36)$ & $P$-value \\
\hline & $\begin{array}{c}\text { Mean } \pm \text { SD or } \\
n(\%)\end{array}$ & $\begin{array}{c}\text { Mean } \pm \text { SD or } \\
n(\%)\end{array}$ & \\
\hline Age (years) & $59.61 \pm 15.92$ & $65.28 \pm 13.89$ & 0.11 \\
\hline $\mathrm{BSA}\left(\mathrm{m}^{2}\right)$ & $1.58 \pm 0.20$ & $1.57 \pm 0.18$ & 0.91 \\
\hline STS score & $\begin{array}{c}\text { Median: 5.59; } \\
\text { range (1.12-44.15) }\end{array}$ & $\begin{array}{l}\text { Median: } 9.52 ; \\
\text { range } \\
(1.16-78.41)\end{array}$ & 0.02 \\
\hline Male & $13(36.1)$ & $16(44.4)$ & 0.63 \\
\hline Diabetes & 7 (19.4) & $8(22.2)$ & 1.00 \\
\hline Dyslipidemia & $18(50.0)$ & $15(41.7)$ & 0.64 \\
\hline AKD & $0(0.0)$ & $2(5.6)$ & - \\
\hline CKD & $11(30.6)$ & 8 (22.2) & 0.59 \\
\hline$H / D$ & $2(5.6)$ & $4(11.1)$ & 0.67 \\
\hline Lung disease & $7(19.4)$ & $10(27.8)$ & 0.58 \\
\hline Liver disease & $1(2.8)$ & $6(16.7)$ & 0.11 \\
\hline CVA & $2(5.6)$ & $6(16.7)$ & 0.26 \\
\hline CAD & $6(16.7)$ & $16(44.4)$ & 0.02 \\
\hline PVD & $1(2.8)$ & $2(5.6)$ & 1.00 \\
\hline Endocarditis history & 7 (19.4) & $4(11.1)$ & 0.51 \\
\hline Old Ml & $1(2.8)$ & $0(0.0)$ & - \\
\hline $\mathrm{PCl}$ & $2(5.6)$ & $6(16.7)$ & 0.26 \\
\hline CABG & $3(8.3)$ & $8(22.2)$ & 0.19 \\
\hline$A F$ & $17(47.2)$ & $20(55.6)$ & 0.64 \\
\hline PPM & $3(8.3)$ & 5 (13.9) & 0.71 \\
\hline LA thrombus & $4(11.1)$ & $2(5.6)$ & 0.67 \\
\hline Arrhythmia & $9(25.0)$ & $4(11.1)$ & 1.00 \\
\hline$A K D+H / D$ & $1(2.8)$ & $1(2.8)$ & 1.00 \\
\hline Indications & & & 0.17 \\
\hline Mitral regurgitation & $6(16.7)$ & $10(27.8)$ & \\
\hline $\begin{array}{l}\text { Isolated mitral } \\
\text { stenosis }\end{array}$ & $26(72.2)$ & $18(50.0)$ & \\
\hline $\begin{array}{l}\text { Mixed mitral } \\
\text { regurgitation and } \\
\text { stenosis }\end{array}$ & $4(11.1)$ & $8(22.2)$ & \\
\hline NYHA & & & 0.04 \\
\hline 2 & 12 (33.3) & $6(16.7)$ & \\
\hline 3 & $19(52.8)$ & $16(44.4)$ & \\
\hline 4 & 5 (13.9) & $14(38.9)$ & \\
\hline $\begin{array}{l}\text { Previous MV } \\
\text { replacement }\end{array}$ & 25 (69.4) & $33(91.7)$ & 0.04 \\
\hline Previous MV repair & $11(30.6)$ & $3(8.3)$ & 0.04 \\
\hline $\begin{array}{l}\text { Previous AV } \\
\text { replacement }\end{array}$ & $5(13.9)$ & $10(28.6)$ & 0.16 \\
\hline Previous TV repair & $14(38.9)$ & 17 (48.6) & 0.48 \\
\hline
\end{tabular}

BSA, body surface area; STS, society of thoracic surgeons; $A K D$, acute kidney disease; $C K D$, chronic kidney disease; H/D, hemodialysis; CVA, cerebrovascular accident; $C A D$, coronary artery disease; PVD, peripheral artery disease; MI, myocardial infarction; $P C l$, percutaneous coronary intervention; $C A B G$, coronary artery bypass graft; $A F$, atrial fibrillation; PPM, permanent pacemaker; LA, left atrium; NYHA, New York Heart Association; MV, mitral valve; $A V$, aortic valve; $T V$, tricuspid valve.

were 5.6, 5.6, 9.8, and 21.9\%, respectively. The statistical significance $(p=0.038)$ of procedure difference was found for cumulative survival.
TABLE 2 | Procedure details in SRMVR or TAMVI approaches.

\begin{tabular}{lc}
\hline SRMVR & $\boldsymbol{n}(\%)$ \\
\hline APPROACH & \\
\hline Median sternotomy & $36(100.0)$ \\
REPLACING VALVE TYPE & \\
Edwards Sapien & $10(27.8)$ \\
ST-JUDE & $16(44.4)$ \\
ON-X & $5(13.9)$ \\
Medtronic-Hancock & $2(5.6)$ \\
SORIN BICARBON & $1(2.8)$ \\
C-E perimount magna mitral ease & $1(2.8)$ \\
Mosaic tissue valve & $1(2.8)$ \\
CONCOMITANT SURGICAL PROCEDURES & \\
\hline Tricuspid valve repair & $6(16.7)$ \\
Ablation for atrial fibrillation & $5(13.9)$ \\
TAMVI & $\boldsymbol{n}(\%)$ \\
APPROACH & \\
Transapical & $36(100.0)$ \\
\hline EEPLACING VALVE TYPE & $7(19.4)$ \\
\hline Boston Scientific Lotus & $6(16.7)$ \\
\hline & $23(63.9)$ \\
\hline & \\
\hline & \\
\hline & \\
\hline
\end{tabular}

The effect of independently associated risk factors upon all-cause mortality among patients after SRMVR or TAMVI surgery was examined using the multiple Cox regression models. As is depicted in Table 7, subsequent to adjustment for confounding factors and IPTW, STS score (Hazard ratio $=1.05$, 95\%CI: 1.01-1.09) appeared to be statistically significantly related to all-cause mortality.

\section{DISCUSSION}

\section{Clinical Implications}

Surgical valve replacement is the gold standard for patients with mitral valve disease or bioprosthesis failure. Nonetheless, recurrent $\mathrm{MR}$ is frequently encountered after mitral valve repair, particularly in the setting of functional MR (3). For most individuals, intervention provides functional improvement and increased survival exceeding that of clinical treatment $(2,14)$. However, many patients (particularly those with comorbidities) require reoperation, which brings with it an elevated risk of surgery-related complications (15-17). Since its introduction in 2009, transcatheter mitral valve-in-valve implantation has been increasingly adopted for the treatment of patients with malfunctioning bioprosthesis (18). Currently, there is a lack of data pertaining to TAMVI, and no direct comparison of TAMVI and SRMVR has been published in Asia. One study reported on 62 patients who underwent TAMVI and 59 patients who underwent SRMVR in three medical centers. They reported no difference between the two groups in terms of mortality at 12month (19). Our results suggest that TAMVI could achieve results comparable to those of SRMVR in terms of 24-month all 
TABLE 3 | The comparisons of in-hospital outcomes between SRMVR and TAMVI groups $(n=72)$.

\begin{tabular}{|c|c|c|c|}
\hline & SRMVR $(n=36)$ & TAMVI $(n=36)$ & $P$-value \\
\hline & $\begin{array}{c}\text { Mean } \pm \text { SD or } n \\
(\%)\end{array}$ & $\begin{array}{c}\text { Mean } \pm \text { SD or } \\
n(\%)\end{array}$ & \\
\hline $\begin{array}{l}\text { Replacing valve inner } \\
\text { diameter (mm) }\end{array}$ & $28.17 \pm 1.88$ & $27.92 \pm 1.52$ & 0.54 \\
\hline Urgent procedure & 7 (19.4) & $2(5.6)$ & 0.08 \\
\hline $\begin{array}{l}\text { Total procedure time } \\
\text { (min) }\end{array}$ & $520.97 \pm 85.56$ & $\begin{array}{c}177.50 \pm \\
115.86\end{array}$ & $<0.001$ \\
\hline CPB time (min) & $181.97 \pm 63.20$ & - & - \\
\hline $\begin{array}{l}\text { Cross-clamp time } \\
\text { (min) }\end{array}$ & $153.39 \pm 66.96$ & - & - \\
\hline Fluoroscopy time (min) & - & $10.00 \pm 2.00$ & - \\
\hline $\begin{array}{l}\text { Amount of contrast } \\
(\mathrm{ml})\end{array}$ & - & 0.00 & - \\
\hline $\begin{array}{l}\text { IABP utilization } \\
\text { (intra-/post-procedure) }\end{array}$ & $3(8.3)$ & $0(0.0)$ & 1.00 \\
\hline Total ICU stay (days) & $6.56 \pm 5.47$ & $4.47 \pm 5.86$ & 0.12 \\
\hline $\begin{array}{l}\text { Length of stay after } \\
\text { procedures (days) }\end{array}$ & $28.47 \pm 12.15$ & $21.89 \pm 8.60$ & 0.01 \\
\hline $\begin{array}{l}\text { Delayed LV apical } \\
\text { pseudoaneurysm }\end{array}$ & $0(0.0)$ & $1(2.8)$ & 1.00 \\
\hline \multicolumn{4}{|l|}{ CLINICAL OUTCOMES } \\
\hline Post-PPM & $2(5.6)$ & $1(2.8)$ & 0.23 \\
\hline In-hospital death & $1(2.8)$ & $0(0.0)$ & 1.00 \\
\hline Minor complication & $2(5.6)$ & $0(0.0)$ & 1.00 \\
\hline $\begin{array}{l}\text { Bleeding } \\
\text { complication }\end{array}$ & $3(8.3)$ & $1(2.8)$ & 0.30 \\
\hline Stroke & $1(2.8)$ & $0(0.0)$ & - \\
\hline Arrhythmia & $9(25.0)$ & $4(11.1)$ & 0.13 \\
\hline LVOT obstruction & $0(0.0)$ & $0(0.0)$ & - \\
\hline
\end{tabular}

PPM, permanent pacemaker.

causes mortality due to this procedure introduces less surgical trauma and is less invasive $(20,21)$. Patients with poor left ventricular function were usually precluded SRMVR. Patients received SRMVR have higher risks of post-operative bleeding, longer ventilator usage time, and longer hospital stay $(22,23)$.

We acknowledge that our findings will have to be confirmed in subsequent research with a larger study population over a longer follow-up period. Note that our findings are also limited by the fact that the mean age in TAMVI group was not higher than in SRMVR group $(p=0.11)$, but the STS Predicted Risk of Mortality scores were higher. Note also that the SRMVR cohort included patients over a far longer period of time (from 1998 to July 2018). Since its introduction, the TAMVI technique has evolved in terms of planning (valve apps, MDCT and 2D, 3D echocardiography) and approach (from transapical), such that the procedure has become more effective, less invasive, and safer. Thus, our overall results may be influenced by difficulties experienced shortly after adoption; however, we were unable to excise the early cases due to the small number of patients in our sample.

Previous evidence-based studies reported mean gradient after TAMVI were $11.3 \pm 5.2$ to $5.5 \pm 3.6 \mathrm{mmHg}, 14.0 \pm 6.5$ to
TABLE 4 | The comparisons of in-hospital outcomes between the two TAVI products $(n=36)$.

\begin{tabular}{|c|c|c|c|}
\hline & $\begin{array}{c}\text { Boston Scientific } \\
\text { Lotus }(n=7)\end{array}$ & $\begin{array}{l}\text { Edward Sapien } \\
\qquad(n=29)\end{array}$ & $P$-value \\
\hline & $\begin{array}{c}\text { Mean } \pm \text { SD or } n \\
(\%)\end{array}$ & $\begin{array}{c}\text { Mean } \pm \text { SD or } \\
n(\%)\end{array}$ & \\
\hline $\begin{array}{l}\text { Replacing valve inner } \\
\text { diameter }(\mathrm{mm})\end{array}$ & $27.29 \pm 0.76$ & $34.97 \pm 37.35$ & 0.17 \\
\hline $\begin{array}{l}\text { Total procedure time } \\
\text { (min) }\end{array}$ & $155.71 \pm 52.08$ & $\begin{array}{c}182.76 \pm \\
126.69\end{array}$ & 0.70 \\
\hline Total ICU stay (days) & $2.57 \pm 2.37$ & $4.93 \pm 6.38$ & 0.14 \\
\hline $\begin{array}{l}\text { Length of stay after } \\
\text { procedures (days) }\end{array}$ & $25.71 \pm 6.60$ & $20.97 \pm 8.86$ & 0.06 \\
\hline \multicolumn{4}{|c|}{ CLINICAL OUTCOMES } \\
\hline Post-PPM & $0(0)$ & $5(17.2)$ & - \\
\hline $\begin{array}{l}\text { Bleeding } \\
\text { complication }\end{array}$ & $0(0)$ & $1(3.4)$ & - \\
\hline Arrhythmia & $0(0)$ & $4(13.8)$ & - \\
\hline
\end{tabular}

PPM, permanent pacemaker.

TABLE 5 | The results for value in ring compare to valve in prosthesis $(n=36)$.

\begin{tabular}{|c|c|c|c|}
\hline & $\begin{array}{c}\text { Failed } \\
\text { annuloplasty } \\
\text { ring }(n=3)\end{array}$ & $\begin{array}{c}\text { Non-failed } \\
\text { annuloplasty } \\
(n=33)\end{array}$ & $P$-value \\
\hline & $\begin{array}{c}\text { Mean } \pm \text { SD or } n \\
(\%)\end{array}$ & $\begin{array}{c}\text { Mean } \pm \text { SD or } n \\
(\%)\end{array}$ & \\
\hline $\begin{array}{l}\text { Replacing valve inner } \\
\text { diameter }(\mathrm{mm})\end{array}$ & $27.00 \pm 1.73$ & $34.06 \pm 35.03$ & 0.27 \\
\hline $\begin{array}{l}\text { Total procedure time } \\
\text { (min) }\end{array}$ & $148.33 \pm 42.53$ & $180.15 \pm 120.34$ & 0.91 \\
\hline Total ICU stay (days) & $12.33 \pm 13.65$ & $3.76 \pm 4.43$ & 0.05 \\
\hline $\begin{array}{l}\text { Length of stay after } \\
\text { procedures (days) }\end{array}$ & $24.67 \pm 8.51$ & $21.64 \pm 8.69$ & 0.51 \\
\hline \multicolumn{4}{|c|}{ CLINICAL OUTCOMES } \\
\hline Post-PPM & $0(0.0)$ & $5(15.2)$ & - \\
\hline $\begin{array}{l}\text { Bleeding } \\
\text { complication }\end{array}$ & 1 (33.3) & $0(0.0)$ & - \\
\hline Arrhythmia & $0(0.0)$ & $4(12.1)$ & - \\
\hline
\end{tabular}

PPM, permanent pacemaker.

$4.7 \pm 3.1 \mathrm{mmHg}$, and $6.3 \pm 2.9$ (immediate) to $7.3 \pm 2.5$ $\mathrm{mmHg}$ after 70, 130 days, and 1 year, respectively. The findings were consistent with our TAMVI results at 3 months from $11.64 \pm 5.98$ to $6.29 \pm 1.80 \mathrm{mmHg}$ at 3 -month, $6.43 \pm 1.91$ $\mathrm{mmHg}$ at 24-month. This noted that the mean gradient after SRMVR includes mechanical and bioprosthetic valves (24-28). In addition, our results suggest that an elevated post-procedural mean gradient can still be a limitation after a transcatheter valve-in-valve procedure in both the aortic and mitral positions, but new techniques, such as transcatheter bioprosthetic valve fracture during TAMVI maybe a solution for patients with a small bioprosthetic valve (29-31). 
TABLE 6 | The details of patients with failed annuloplasty rings $(n=3)$.

\begin{tabular}{|c|c|c|c|c|c|c|c|}
\hline No & Age & Valve type & $\begin{array}{l}\text { Baseline } \\
\text { STS score }\end{array}$ & $\begin{array}{l}\text { Baseline } \\
\text { NYHA class }\end{array}$ & $\begin{array}{l}\text { No. of prior } \\
\text { thoracotomies }\end{array}$ & Comorbidities & $\begin{array}{l}\text { Clinical } \\
\text { outcomes }\end{array}$ \\
\hline 1 & 72 & Boston Scientific Lotus & 14.24 & IV & 1 & $\begin{array}{l}\text { History of mitral valve } \\
\text { repaired, HTN, dyslipidemia, } \\
\text { CKD, CAD, PCI, AF }\end{array}$ & Alive \\
\hline 2 & 81 & Edwards Sapien XT & 73.67 & IV & 1 & $\begin{array}{l}\text { History of mitral valve repaired, } \\
C K D, H / D \text {, lung disease, CAD, } \\
\text { PCI, CABG, PPM, bleeding } \\
\text { complication }\end{array}$ & $\begin{array}{l}\text { Expired } \\
\text { (21days) }\end{array}$ \\
\hline 3 & 64 & Edwards Sapien XT & 5.25 & III & 1 & $\begin{array}{l}\text { History of Mitral Valve Repaired, } \\
\text { HTN, CAD, AF }\end{array}$ & Alive \\
\hline
\end{tabular}

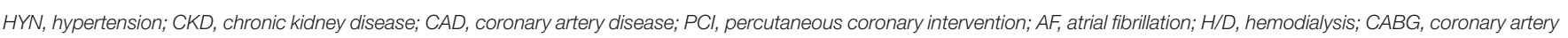
bypass graft; PPM, permanent pacemaker; STS, society of thoracic surgeons; NYHA, New York Heart Association.

There is always a risk of left ventricular outflow tract obstruction after TAMVI or SRMVR, due to interference from the surgical implant/TAMVI frame or paradoxical septal motion in patients with right ventricular volume overload following surgery. None of the patients in the current study presented LVOT obstruction after TAMVI (0\%), most likely due to preprocedural planning using 2D and 3D TEE and MDCT $(32,33)$.

The original idea for valve-in-ring procedures was proposed by Wilbring et al. (34). The most recent series was published by Urena et al. in which 30 Edward Sapien XT and Sapien 3 valves were implanted (35). Post-operative echocardiography results revealed hemodynamic outcomes. Note that valve sizing (and particularly determining the inner diameter) is essential to the success of valve-in-ring procedures; however, it remains the most challenging aspect of the procedure. We used the ring area provided by the manufacturer to estimate the internal diameter, under the assumption that the ring area and circumference would remain constant even after TAMVI implantation. Unfortunately, annuloplasty rings are semi-rigid, and a TAMVI is not capable of reshaping after implantation. Surprisingly, these gaps appear not to have any effect in implantations in terms of paravalvular leakage. We assume that surrounding valvular tissue or pannus formation seal these gaps. All valve-in-ring procedures in our series produced excellent hemodynamic results with good prosthesis function.

Concomitant surgical tricuspid repair is recommended for patients with more than mild tricuspid regurgitation at the time of mitral valve surgery, due to the fact that it does not increase the risk of operative mortality (36-38). Nonetheless, its effect on clinical long-term outcome remains an issue of controversy, despite acute echocardiographic improvement (3941). Interestingly, in this study, for all SRMVR and TAMVI patients who did not undergo any tricuspid procedures $(22$ vs. 19), reductions of TR were similar (Figure 4) in 12month mortality.

There are only limited cases in valve-in-ring, and mostly done by complete ring. The sizing guidance is according to the mitral VIV app developed by Bapat et al. incorporation with the technology company UBQO (42). We also performed the bench test according to the sizing chart of the app. Usually, oversizing
$20 \%$ of the correspondent valve area by overfilling the balloon was done. All these valve-in-ring cases received surgical complete ring (case1: Edwards classic ring; case 2: Edwards Physio I ring; case 3: Sorin Memo 3D). In our bench test, the Edwards classic and Physio ring could be fitted by oversizing the implanted valve. However, Sorin Memo 3D remained some paravalvular space and resulted in paravalvular leakage.

Yoon et al. Reported in the TMVR registry only $80-90 \%$ success with relative lower success in the valve in ring group than our results (2). There are several important issues to success in our series. First, patients received pre-operative 4-D MSCT. The neo-LVOT, especially in mitral-valve-ring, was analyzed before surgery. If the neo-LVOT is $<30 \%$ of original LVOT, we suggested patients should receive redo-surgery. Second, we performed all procedures from transapical access. We belief transapical access providing better coaxiality than transseptal access. Besides, there are several cases received mitral procedure from trans-septal approach and bi-atrial approaches during first open heart surgery. It makes mitral valve-invalve and valve-in-ring procedures from trans-septal approach more difficult. Currently, the procedure time of transapical mitral valve-in-valve and valve-in-ring procedures was $<3 \mathrm{~h}$. And there was only one case with apical pseudoaneurysm formation. Third, all patients received general anesthesia and transesophageal echocardiography. We belief additional TEE image providing neo-LVOT size and gradient. And also TEE monitoring the depth of the devices and prevent left atrial or left ventricle embolization.

We had a 58-year-old male patient who underwent TAMVI with a $26 \mathrm{~mm}$ Sapien 3 valve. After discharge, he remained symptom-free for a period of 3 weeks, at which point he began complaining of shortness of breath. Echocardiographic analysis revealed a large pseudoaneurysm in the left ventricular apex region. The patient subsequently underwent transcatheter closure of the pseudoaneurysm using an $18 \mathrm{~mm}$ Amplatzer atrial septal defect occluder (St. Jude Medical). As results indicated in previous mitral transcatheter studies, prescribing warfarin may prevent early valve thrombosis; however, there is no clear evidence to prevent the pseudoaneurysm in patients (25, 33). The Coumadin was routinely prescript in valve-in-valve, 


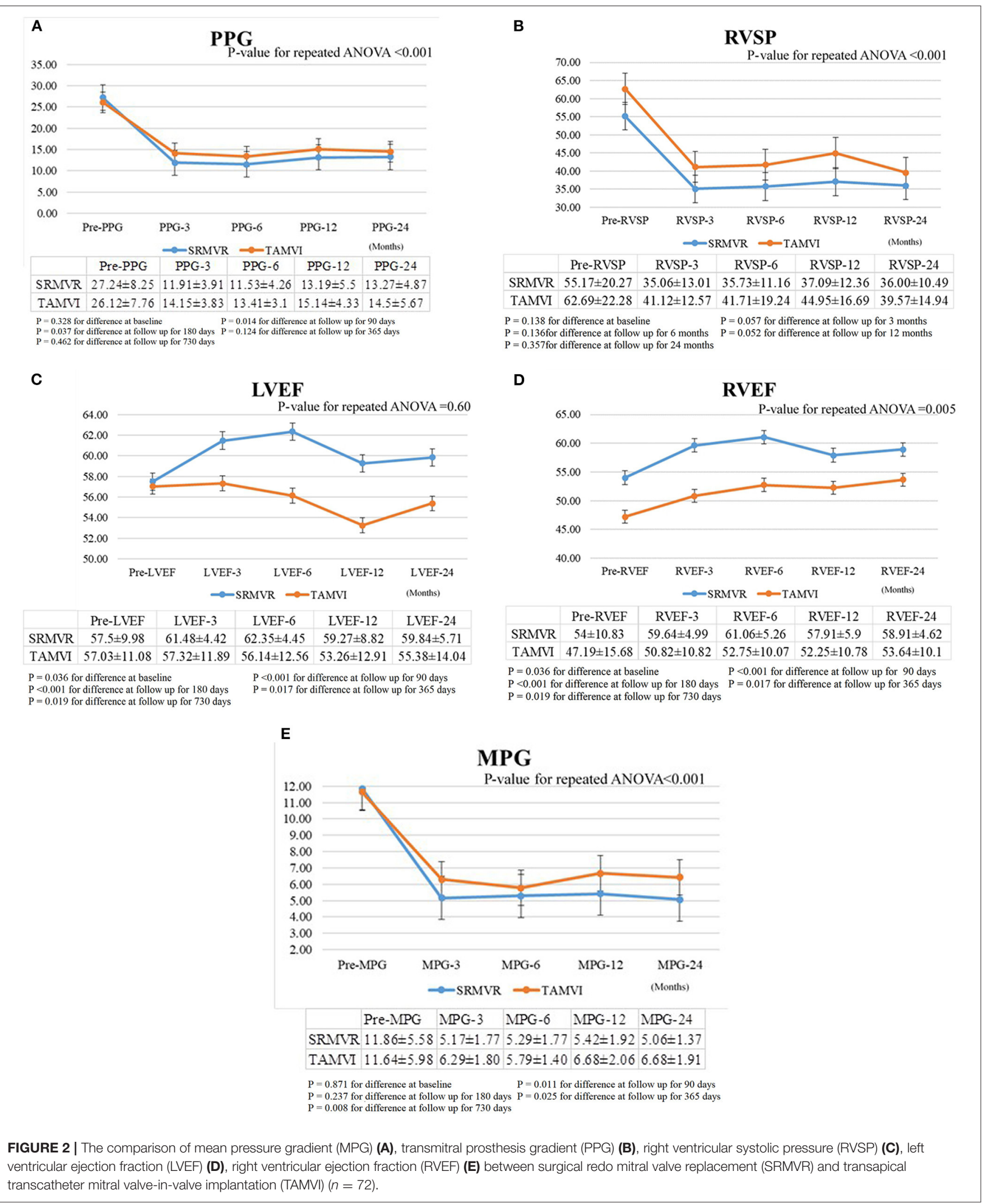




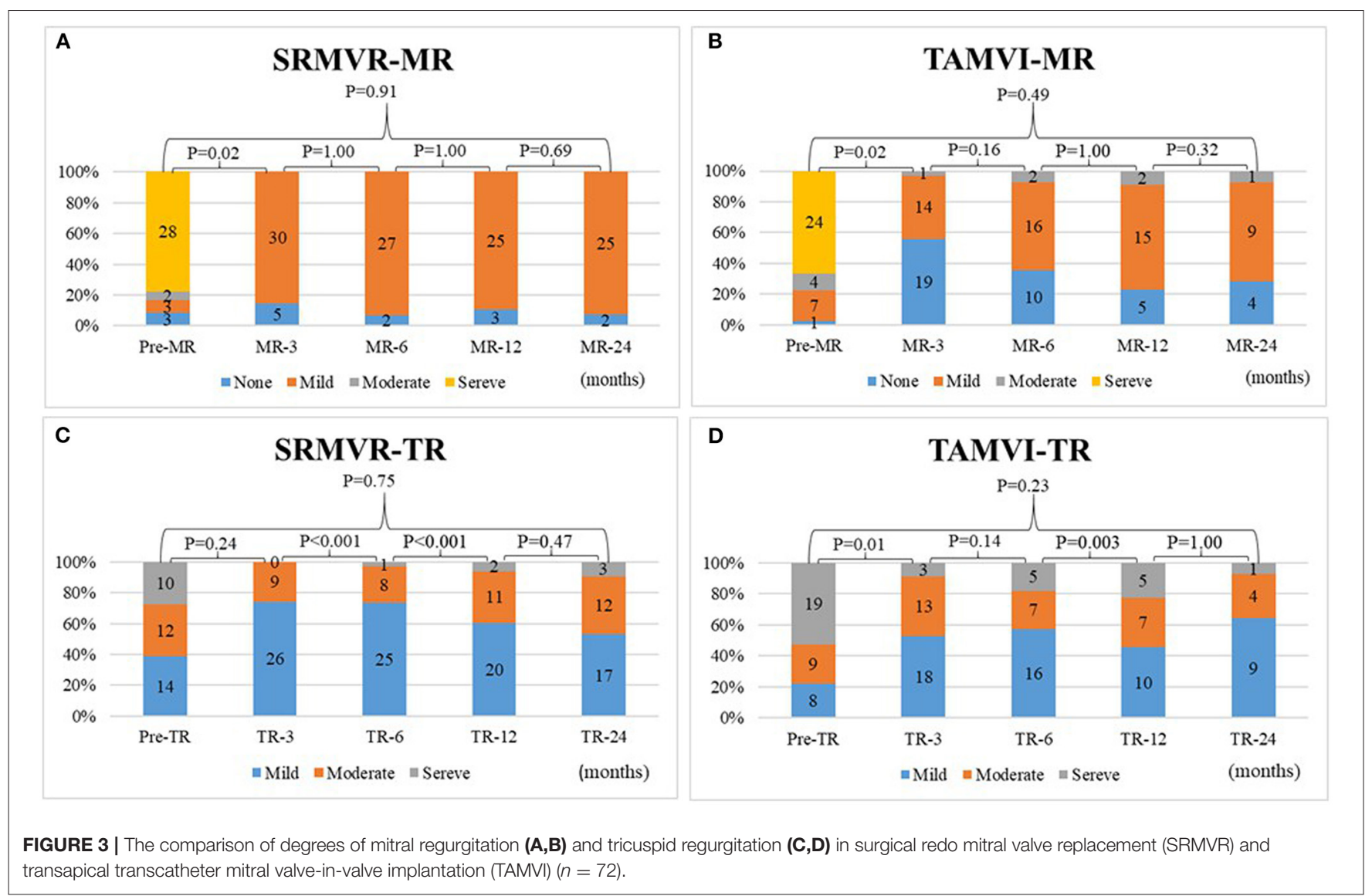

valve-in-ring, and valve-in-calcification cases. When patients have bleeding problems, the coumadin was stopped and used antiplatelets only. We believe anticoagulation was indicated in these cases due to most of these cases have atrial fibrillation. In additional to these reasons, trans-mitral blood flow is lower and higher residual trans-mitral pressure gradient in these cases.

In addition, Figures $\mathbf{3 A}, \mathbf{B}$ indicates that vast majority of patients after surgical redo MVR appear to have mild regurgitation. The implanted Edwards mitral pericardial valve tend to have mild central valvular regurgitation. In our observation and literatures, this mild regurgitation did not have effect on short-term and long-term outcome $(43,44)$. We also found the Edwards Sapien valve has the same regurgitation esp. in previous generation of Sapien XT (45). This implies that the central regurgitation is a common finding related to Edwards bovine pericardial valve and does not effect short- and long-term durability of this bioprosthesis.

\section{Study Limitations}

Although the main strength was that we tried to accommodate inherent selection biases with IPTW, the primary limitation of this study was the small number of patients, which may have limited the power to detect significant differences. The decision of whether to adopt TAMVI or SRMVR was made by the heart team in conjunction with the patient. It is likely that this approach introduced bias that could affect outcomes. We made

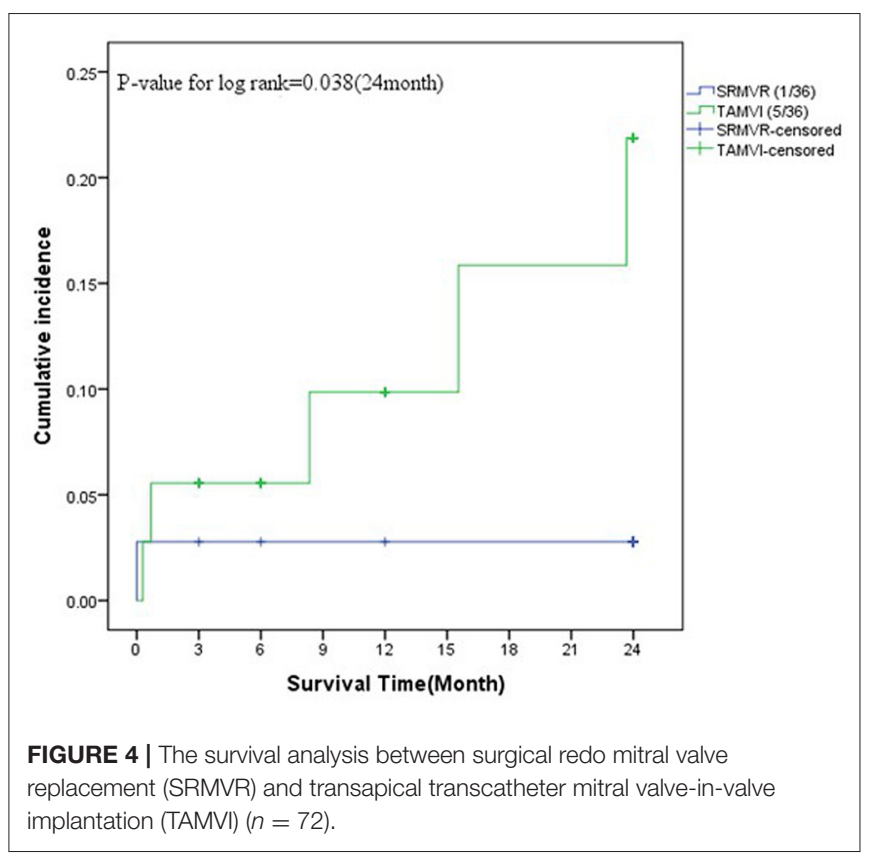

our comparison as homogeneous as possible. However, there are still some differences that may influence the outcomes, including the incidence of new arrhythmias or other side-effects. Second, 
TABLE 7 | Multivariate analysis using Cox regression model of risk factors associated with the all-cause mortality after adjustment for inverse probability of treatment weighting (IPTW) among patients with SRMVR or TAMVI surgery $(n=72)$.

\begin{tabular}{|c|c|c|c|c|c|}
\hline \multirow[t]{2}{*}{ Variables } & \multicolumn{5}{|c|}{ All causes of death (yes vs. no) } \\
\hline & $\beta$ & SE & $P$-value & Hazard ratio & $95 \%$ confidence interval \\
\hline STS score & 0.05 & 0.02 & 0.01 & 1.05 & $1.01-1.09$ \\
\hline Operation (TAMVI vs. SRMVR) & 2.91 & 1.74 & 0.09 & 18.41 & $0.61-553.92$ \\
\hline Procedure time & 0.004 & 0.003 & 0.21 & 1.004 & $0.998-1.011$ \\
\hline IPTW & 0.07 & 0.25 & 0.78 & 1.07 & $0.65-1.77$ \\
\hline
\end{tabular}

our inability to collect details related to the initial SRMVR procedures (many files were missing) may have affected the echocardiographic results and clinical outcomes. Third, fewer SRMVR patients underwent echocardiographic examinations at the time of discharge or during follow-up. The fact that we included patients who underwent SRMVR prior to the advent of TAMVI ( $80 \%$ of SRMVR procedures were performed between 1998 and 2013) meant that we had access to far more follow-up information for SRMVR patients than TAMVI patients. Finally, the perioperative mortality associated with redo mitral surgery is relatively lower than the reiterative mortality seen in the state of New York and Virginia $(46,47)$. The TAMVI mortality is also lower than that reported by Yoon et al. from the TMVR registry (2). Further long-term studies with a larger number of patients will be required to accurately assess the efficacy of TAMVI.

\section{CONCLUSIONS}

In conclusion, this is a retrospective cohort study from Taiwan examining SRMVR in comparison with TAMVI. Transcatheter techniques will play a large role in the management of SVD in the future with the rapid increase in the use of bioprosthetic valves in younger and younger patients. The statistical analysis is still not robust enough to make a claim that TAMVI is an appropriate alternative. The outcome of the patient appears only to be related

\section{REFERENCES}

1. Spaccarotella C, Mongiardo A, De Rosa S, Indolfi C. Transcatheter aortic valve implantation in patients at intermediate surgical risk. Int J Cardiol. (2017) 243:161-8. doi: 10.1016/j.ijcard.2017.04.107

2. Yoon SH, Whisenant BK, Bleiziffer S, Delgado V, Dhoble A, Schofer $\mathrm{N}$, et al. Outcomes of transcatheter mitral valve replacement for degenerated bioprostheses, failed annuloplasty rings, and mitral annular calcification. Eur Heart J. (2019) 40:441-51. doi: 10.1093/eurheartj/ ehy590

3. Goldstein D, Moskowitz AJ, Gelijns AC, Ailawadi G, Parides MK, Perrault LP, et al. Two-year outcomes of surgical treatment of severe ischemic mitral regurgitation. N Engl J Med. (2016) 374:344-53. doi: 10.1056/NEJMoa1512913

4. Whisenant B, Kapadia SR, Eleid MF, Kodali SK, McCabe JM, Krishnaswamy A, et al. One-year outcomes of mitral valve-in-valve using the SAPIEN 3 transcatheter heart valve. JAMA Cardiol. (2020) 5:1245-52. doi: 10.1001/jamacardio.2020.2974

5. Urena M, Vahanian A, Brochet E, Ducrocq G, Iung B, Himbert D. Current indications for transcatheter mitral valve replacement using transcatheter aortic valves: valve-in-valve, valve-in-ring, to the patient's pre-operative STS score. Equivalence has not been demonstrated, as a non-inferiority study would be required for such a claim to be made. The most that might be able to be said is that at our institution TAMVI has been a viable alternative in patients with adequate access and appropriate LVOT dimensions. For this reason, accumulating single institution reports are an important piece of the overall puzzle that will necessarily include larger scale examinations.

\section{DATA AVAILABILITY STATEMENT}

The data analyzed in this study is subject to the following licenses/restrictions: the database need permission from the hospital. Requests to access these datasets should be directed to jengwei@mac.com.

\section{AUTHOR CONTRIBUTIONS}

M-CH, W-HY, P-EC, T-HT, and JW conducted the study and drafted the manuscript. M-CH, P-EC, and T-HT participated in the design of the study and performed statistical analyses. Y-TL, T-PT, K-CL, K-CH, and W-HC conceived the study and participated in its design and coordination. All authors read and approved the final manuscript. and valve-in-mitral annulus calcification. Circulation. 143:178-96. doi: 10.1161/CIRCULATIONAHA.120.048147

6. Lang RM, Badano LP, Mor-Avi V, Afilalo J, Armstrong A, Ernande L, et al. Recommendations for cardiac chamber quantification by echocardiography in adults: an update from the American Society of echocardiography and the European Association of Cardiovascular Imaging. Eur Heart J Cardiovasc Imaging. (2015) 16:233-70. doi: 10.1093/ehjci/jev014

7. Stone GW, Vahanian AS, Adams DH, Abraham WT, Borer JS, Bax JJ, et al. Clinical trial design principles and endpoint definitions for transcatheter mitral valve repair and replacement: part 1: clinical trial design principles a consensus document from the Mitral Valve Academic Research Consortium. J Am Coll Cardiol. (2015) 66:278-307. doi: 10.1016/j.jacc.2015.05.046

8. Stone GW, Vahanian AS, Adams DH, Abraham WT, Borer JS, Bax JJ, et al. Clinical trial design principles and endpoint definitions for transcatheter mitral valve repair and replacement: part 2: endpoint definitions a consensus document from the Mitral Valve Academic Research Consortium. J Am Coll Cardiol. (2015) 66:308-21. doi: 10.1016/j.jacc.2015.05.049

9. Cerillo AG, Gasbarri T, Celi S, Murzi M, Trianni G, Ravani M, et al. Transapical transcatheter valve-in-valve implantation for failed mitral bioprostheses: gradient, symptoms, and functional status in 18 
high-risk patients up to 5 years. Ann Thorac Surg. (2016) 102:128995. doi: 10.1016/j.athoracsur.2016.03.051

10. Ye J, Cheung A, Yamashita M, Wood D, Peng D, Gao M, et al. Transcatheter aortic and mitral valve-in-valve implantation for failed surgical bioprosthetic valves: an 8-year single-center experience. JACC Cardiovasc Interv. (2015) 8:1735-44. doi: 10.1016/j.jcin.2015.08.012

11. Wilbring M, Alexiou K, Tugtekin SM, Sill B, Hammer P, Schmidt $\mathrm{T}$, et al. Transapical Transcatheter Valve-in-Valve Implantation for deteriorated mitral bioprostheses. Ann Thorac Surg. (2013) 95:111-7. doi: 10.1016/j.athoracsur.2012.08.004

12. Bapat V, Pirone F, Kapetanakis S, Rajani R, Niederer S. Factors influencing left ventricular outflow tract obstruction following a mitral valve-in-valve or valve-in-ring procedure, part 1. Catheter Cardiovasc Interv. (2015) 86:74760. doi: $10.1002 / \mathrm{ccd} .25928$

13. Benedetto U, Head SJ, Angelini GD, Blackstone EH. Statistical primer: propensity score matching and its alternatives. Eur J Cardiothorac Surg. (2018) 53:1112-7. doi: 10.1093/ejcts/ezy167

14. Murzi M, Berti S, Gasbarri T, Trianni G, Maffei S, Solinas M, et al. Transapical transcatheter mitral valve-in-valve implantation versus minimally invasive surgery for failed mitral bioprostheses. Interact Cardiovasc Thorac Surg. (2017) 25:57-61. doi: 10.1093/icvts/ivx067

15. Barnett SD, Ad N. Surgery for aortic and mitral valve disease in the United States: a trend of change in surgical practice between 1998 and 2005. J Thorac Cardiovasc Surg. (2009) 137:1422-9. doi: 10.1016/j.jtcvs.2008.08.071

16. Jamieson W, Burr LH, Miyagishima RT, Janusz MT, Fradet GJ, Ling H, et al. Re-operation for bioprosthetic aortic structural failure-risk assessment. Eur $J$ Cardiothorac Surg. (2003) 24:873-8. doi: 10.1016/S1010-7940(03)00566-9

17. Jones JM, O'kane H, Gladstone DJ, Sarsam MA, Campalani G, MacGowan SW, et al. Repeat heart valve surgery: risk factors for operative mortality. $J$ Thorac Cardiovasc Surg. (2001) 122:913-8. doi: 10.1067/mtc.2001.116470

18. Seeburger J, Borger MA, Falk V, Passage J, Walther T, Doll $\mathrm{N}$, et al. Minimally invasive mitral valve surgery after previous sternotomy: experience in 181 patients. Ann Thorac Surg. (2009) 87:709-14. doi: 10.1016/j.athoracsur.2008.11.053

19. Kamioka N, Babaliaros V, Morse MA, Frisoli T, Lerakis S, Iturbe JM, et al. Comparison of clinical and echocardiographic outcomes after surgical redo mitral valve replacement and transcatheter mitral valve-in-valve therapy. JACC Cardiovasc Interv. (2018) 11:1131-8. doi: 10.1016/j.jcin.2018.03.011

20. Dai H, Huenges K, Pokorny S, Fischer G, Cremer J, Metzner A, et al. Transcatheter mitral valve implantation: a percutaneous transapical system. Interact Cardiovasc Thorac Surg. (2017) 24:527-33. doi: 10.1093/icvts/ivw399

21. Bouleti C, Fassa AA, Himbert D, Brochet E, Ducrocq G, Nejjari M, et al. Transfemoral implantation of transcatheter heart valves after deterioration of mitral bioprosthesis or previous ring annuloplasty. JACC Cardiovasc Interv. (2015) 8:83-91. doi: 10.1016/j.jcin.2014.07.026

22. Pieri M, Belletti A, Monaco F, Pisano A, Musu M, Dalessandro V, et al. Outcome of cardiac surgery in patients with low preoperative ejection fraction. BMC Anesthesiol. (2016) 16:97. doi: 10.1186/s12871-0160271-5

23. Akay TH, Gultekin B, Ozkan S, Aslim E, Uguz E, Sezgin A, et al. Mitral valve replacements in redo patients with previous mitral valve procedures: mid-term results and risk factors for survival. J Card Surg. (2008) 23:41521. doi: 10.1111/j.1540-8191.2008.00630.x

24. Eleid MF, Whisenant BK, Cabalka AK, Williams MR, Nejjari M, Attias D, et al. Early outcomes of percutaneous transvenous transseptal transcatheter valve implantation in failed bioprosthetic mitral valves, ring annuloplasty, and severe mitral annular calcification. JACC Cardiovasc Interv. (2017) 10:193242. doi: 10.1016/j.jcin.2017.08.014

25. Yoon SH, Whisenant BK, Bleiziffer S, Delgado V, Schofer N, Eschenbach L, et al. Transcatheter mitral valve replacement for degenerated bioprosthetic valves and failed annuloplasty rings. J Am Coll Cardiol. (2017) 70:112131. doi: 10.1016/j.jacc.2017.07.714

26. Gallo M, Dvir D, Demertzis S, Pedrazzini G, Berdajs D, Ferrari E. Transcatheter valve-in-valve implantation for degenerated bioprosthetic aortic and mitral valves. Expert Rev Med Dev. (2016) 13:749-58. doi: 10.1080/17434440.2016.1207521

27. Cheung AW, Gurvitch R, Ye J, Wood D, Lichtenstein SV, Thompson C, et al. Transcatheter transapical mitral valve-in-valve implantationsfor a failed bioprosthesis: a case series. J Thorac Cardiovasc Surg. (2011) 141:7115. doi: 10.1016/j.jtcvs.2010.11.026

28. Seiffert M, Conradi L, Baldus S, Schirmer J, Knap M, Blankenberg $S$, et al. Transcatheter mitral valve-in-valve implantation in patients with degenerated bioprostheses. JACC Cardiovasc Interv. (2012) 5:3419.22. doi: 10.1016/j.jcin.2011.12.008

29. Kamioka N, Corrigan F, Iturbe JM, Caughron H, Lerakis S, Thourani $\mathrm{V}$, et al. Mitral bioprosthetic valve fracture: bail-out procedure for undersized bioprosthesis during mitral valvein- valve procedure with paravalvular leak closure. JACC Cardiovasc Interv. (2018) 11:e21-2. doi: 10.1016/j.jcin.2017.10.047

30. Chhatriwalla AK, Allen KB, Saxon JT, Cohen DJ, Aggarwal S, Hart AJ, et al. Bioprosthetic valve fracture improves the hemodynamic results of valve-invalve transcatheter aortic valve replacement. Circ Cardiovasc Interv. (2017) 10:e005216. doi: 10.1161/CIRCINTERVENTIONS.117.005216

31. Dvir D, Webb J. Mitral valve-in-valve and valve-in-ring: technical aspects and procedural outcomes. EuroIntervention. (2016) 12:Y93-6. doi: 10.4244/EIJV12SYA25

32. Guerrero M, Salinger M, Pursnani A, Pearson P, Lampert M, Levisay J, et al. Transseptal transcatheter mitral valve-in-valve: A step by step guide from preprocedural planning to postprocedural care. Catheter Cardiovasc Interv. (2018) 92:E185-96. doi: 10.1002/ccd.27128

33. Urena $M$, Himbert $D$, Brochet $E$, Carrasco JL, Iung $B$, Nataf $P$, et al. Transseptal transcatheter mitral valve replacement using balloon-expandable transcatheter heart valves. JACC Cardiovasc Interv. (2017) 10:190519. doi: $10.1016 /$ j.jcin.2017.06.069

34. Wilbring M, Alexiou K, Tugtekin SM, Arzt S, Ibrahim K, Matschke $\mathrm{K}$, et al. Pushing the limits-further evolutions of transcatheter valve procedures in the mitral position, including valve-in-valve, valve-inring, and valve-in-native-ring. J Thorac Cardiovasc Surg. (2014) 147:2109. doi: 10.1016/j.jtcvs.2013.09.021

35. Urena M, Brochet E, Lecomte M, Kerneis C, Carrasco JL, Ghodbane W, et al. Clinical and haemodynamic outcomes of balloon-expandable transcatheter mitral valve implantation: a 7-year experience. Eur Heart J. (2018) 39:267989. doi: 10.1093/eurheartj/ehy271

36. Nishimura RA, Otto CM, Bonow RO, Carabello BA, Erwin JP 3rd, Guyton RA, et al. 2014 AHA/ACC guideline for the management of patients with valvular heart disease: executive summary: a report of the American College of Cardiology/American Heart Association Task Force on Practice Guidelines. J Am Coll Cardiol. (2014) 63:2438-88. doi: 10.1016/j.jacc.2014. 02.537

37. Baumgartner H, Falk V, Bax JJ, De Bonis M, Hamm C, Holm PJ, et al. 2017 ESC/EACTS guidelines for the management of valvular heart disease. Eur Heart J. (2017) 38:2739-91. doi: 10.1093/eurheartj/ ehx391

38. Badhwar V, Rankin JS, He M, Jacobs JP, Furnary AP, Fazzalari FL, et al. Performing concomitant tricuspid valve repair at the time of mitral valve operations is not associated with increased operative mortality. Ann Thorac Surg. (2017) 103:587-93. doi: 10.1016/j.athoracsur.2016. 06.004

39. Chan V, Burwash IG, Lam BK, Auyeung T, Tran A, Mesana TG, et al. Clinical and echocardiographic impact of functional tricuspid regurgitation repair at the time of mitral valve replacement. Ann Thorac Surg. (2009) 88:1209-15. doi: 10.1016/j.athoracsur.2009.06.034

40. Im JB, Yoo DG, Kim GS, Song H, Jung SH, Choo SJ, et al. Mild-tomoderate functional tricuspid regurgitation in patients undergoing valve replacement for rheumaticmitral disease: the influence of tricuspid valve repair on clinical and echocardiographic outcomes. Heart. (2012) 98:2430. doi: 10.1136/heartjnl-2011-300403

41. Bianchi G, Solinas M, Bevilacqua S, Glauber M. Which patient undergoing mitral valve surgery should also have the tricuspid repair? Interact Cardiovasc Thorac Surg. (2009) 9:1009-20. doi: 10.1510/icvts.2009.217570

42. Bapat V. Valve-in-valve apps: why and how they were developed and how to use them. EuroIntervention. (2014) 10:U44-51. doi: 10.4244/EIJV1 0SUA7

43. Goetze S, Brechtken J, Agler DA, Thomas JD, Sabik JF III, Jaber WA. In vivo short-term doppler hemodynamic profiles of 189 CarpentierEdwards perimount pericardial bioprosthetic valves in the mitral 
position. J Am Soc Echcardiogr. (2004) 17:981-7. doi: 10.1016/j.echo.2004. 05.006

44. Firstenberg MS, Morehead AJ, Thomas JD, Smedira NG, Cosgrove DM III, Marchand MA. Short-term hemodynamic performance of the mitral Carpentier-Edwards perimount pericardial valve. CarpentierEdwards PERIMOUNT Investigators. Ann Thorac Surg. (2001) 71:S285-8. doi: 10.1016/S0003-4975(01)02514-0

45. Evin M, Guivier-Curien C, Rieu R, Rodés-Cabau J, Pibarot P. Mitral valve-in-valve hemodynamic performance: an in vitro study. $J$ Thorac Cardiovasc Surg. (2016) 151:1051-59.e6. doi: 10.1016/j.jtcvs.2015. 11.039

46. Chikwe J, Chiang YP, Egorova NN, Itagaki S, Adams DH. Survival and outcomes following bioprosthetic vs mechanical mitral valve replacement in patients aged 50 to 69 years. JAMA. (2015) 313:1435-42. doi: 10.1001/jama.2015.3164
47. Mehaffey HJ, Hawkins RB, Schubert S, Fonner C, Yarboro LT, Quader M, et al. Contemporary outcomes in reoperative mitral valve surgery. Heart. (2018) 104:652-6. doi: 10.1136/heartjnl-2017-312047

Conflict of Interest: The authors declare that the research was conducted in the absence of any commercial or financial relationships that could be construed as a potential conflict of interest.

Copyright (c) 2021 Hsiung, Yin, Lee, Tsao, Lee, Huang, Chen, Chiang, Tung and Wei. This is an open-access article distributed under the terms of the Creative Commons Attribution License (CC BY). The use, distribution or reproduction in other forums is permitted, provided the original author(s) and the copyright owner(s) are credited and that the original publication in this journal is cited, in accordance with accepted academic practice. No use, distribution or reproduction is permitted which does not comply with these terms. 